\title{
ANTROPOLOGÍA JURÍDICA
}

\section{Benjamín Rivaya ${ }^{1}$}

\section{Resumen}

La antropología jurídica es aquella parte de la antropología social o cultural que se dedica al estudio, comparativo y de largo alcance, de la organización social y, en concreto, del Derecho. Cuestión fundamental para esta antropología es la del concepto del Derecho, pues lo necesita para delimitar su objeto. Al respecto, la polémica entre Malinowski y Radcliffe-Brown resulta clásica, como clásica es la polémica entre Gluckman y Bohannan, sobre el método de la antropología jurídica. Dos temas nucleares de la antropología del Derecho son el de la universalidad de éste y el de los rasgos, tanto universales como particulares, de los órdenes jurídicos. En el presente, el estudio comparativo de los derechos humanos convierte a esta antropología en indispensable.

Palabras clave: Antropología jurídica; concepto de derecho; derecho primitivo; método antropológico jurídico; universalidad del derecho; rasgos universales del Derecho; rituales jurídicos; derechos humanos.

\section{Introducción}

Etimológicamente, el término "antropología" se refiere al estudio del hombre, si bien este estudio puede ser de diverso tipo, abarcando la palabra tanto la antropología física o biológica, como la social o cultural, y la filosófica. Aunque es cierto que, aun de diversa manera, todas ellas guardan relación con el Derecho, sin duda la antropología jurídica forma parte de la que hemos llamado social o cultural, entendiendo por ésta la que estudia las culturas humanas de una forma global y comparativa, con lo que ya desde el inicio los

\footnotetext{
${ }^{1}$ Catedrático de Filosofía del Derecho de la Universidad de Oviedo. Decano de la Facultad de Derecho de la Universidad de Oviedo entre 2012 y 2016. Líneas de invesitgación: Historia del pensamiento jurídico español. Filosofía política. Derecho y cine. Antropología jurídica. Universidad de Oviedo - Espanha. ORCIC iD: http://orcid.org/0000-0002-0938-4923. E-mail: rivaya@uniovi.es
} 
antropólogos entienden el Derecho como realidad cultural, a la vez que se ven en la tesitura de tener que diferenciar entre la naturaleza y la cultura humanas, cuestión a la que reenvía un buen número de enigmas culturales y que resulta de sumo interés también para el pensamiento jurídico.

En cuanto al Derecho, ese peculiar fenómeno normativo, es objeto de estudio de diversas ciencias sociales o humanas. En tanto que fenómeno social, es objeto de la sociología; en tanto que cultural, de la antropología; en tanto que histórico, de la historia. Hay otras posibilidades, pero estas tres perspectivas son las que dan lugar a las ciencias sociojurídicas fundamentales: la sociología del Derecho, la antropología jurídica y la historia del Derecho. En muchas ocasiones, los límites que separan los diversos puntos de vista que utilizan las ciencias socio-jurídicas se difuminan hasta casi desaparecer; téngase en cuenta que los criterios que tendrían que manejarse para diferenciar esos saberes jurídicos serían espacio-temporales (dentro/ fuera, cerca/ lejos), y darían lugar a muchas posibilidades, algunas claramente distinguibles pero otras casi iguales, difícilmente diferenciables (Ferrari 2000: 81-86): una sociología del Derecho medieval ¿sería sociología o historia?; una historia completa del Derecho ¿sería historia o antropología jurídica?; un estudio de la mentalidad jurídica de ciertos grupos marginales de una sociedad avanzada contemporánea, ¿constituiría una investigación de antropología o de sociología del Derecho?; el estudio del Derecho azteca o maya, ¿corresponde a la historia o a la antropología jurídicas?, etc. En concreto y a título de ejemplo, cuando Boaventura de Sousa Santos, en 1970, se trasladó a una favela de Río de Janeiro a estudiar los servicios legales para los pobres en Brasil (Santos 2009: 216 ss), ¿estaba haciendo sociología o antropología del Derecho? En fin, las ciencias socio-jurídicas fundamentales comparten el mismo objeto de conocimiento, el estudio de las instituciones y los órdenes jurídico "en su génesis, evolución y efectos prácticos” (Arnaud y Fariñas 1996: 30 ); comparten el mismo objeto -digo-, lo que hace que se confundan y amalgamen, que cambien y se borren sus fronteras o, incluso, que aparezcan otras nuevas.

Por otra parte, así como se ha dicho que hay una sociología del Derecho elaborada por sociólogos y otra por juristas, y lo mismo se podría decir por analogía de la filosofía del Derecho, la historia del Derecho, etc., ¿sucede otro tanto con la antropología jurídica? En este punto convendría acudir a la historia del saber antropológico, pues ocurre que sus primeros cultivadores fueron juristas interesados por el estudio del mundo primitivo: Bachofen (18151887), Morgan (1818-1881), Maine (1822-1888) o McLennan (1827-1881). Posteriormente, sin embargo, las grandes obras de la antropología jurídica fueron escritas por antropólogos interesados en el Derecho: Malinowski (1884-1942), Radcliffe-Brown (1881-1955), Hoebel 
(1906-1993), Gluckman (1911-1975), Bohannan (1920-2007), Pospisil (1923), Nader (1930), etc. Quizás lo deseable sería un encuentro entre antropólogos y juristas ${ }^{2}$, pues se pueden aportar ideas y métodos recíprocamente, como ocurrió en 1941, en el estudio sobre el Derecho cheyenne fruto de la colaboración entre Karl Llewellyn y E. Adamson Hoebel (2002).

Pero además de que haya una antropología elaborada por juristas y una antropología jurídica hecha por antropólogos, se puede entender la antropología del Derecho de dos maneras distintas. Por una parte está la antropología jurídica en sentido estricto, que abarca el trabajo de campo en un pueblo determinado y la posterior exposición de su orden jurídico y, en su caso, la labor comparativa. El ejemplo paradigmático de esta antropología es el de Malinowski, con su estudio del Derecho de las islas Trobiand, sintetizado magistralmente en 1926, en Crime and Custom in Savage Society (1991). Por otra parte es posible la aplicación al estudio del Derecho del método establecido por una corriente antropológica determinada y así crear el evolucionismo jurídico, el materialismo jurídico, el particularismo jurídico, el difusionismo jurídico, el estructuralismo jurídico, etc. En todos los casos citados basta con establecer las reglas del método de esas antropologías y utilizarlas luego para estudiar ese objeto específico que es el Derecho, enriqueciéndose así su estudio con nuevos conceptos y clasificaciones; a título de ejemplo, seguro que hoy día habrá quien distinga entre el Derecho paterno y el materno, haciendo uso de la diada de Bachofen; habrá quien utilice para estudiar el fenómeno jurídico las perspectivas emic y etic, de Pike; habrá quien plantee la relación del Derecho con el salvajismo, la barbarie y la civilización, estadios de la humanidad legados por Morgan; habrá quien ponga en relación el Derecho con la economía y la demografía, con la ecología y la tecnología, con la política y la religión, con el arte y los ritos, etc. Baste como ejemplo, entre otros muchos, el uso del método del materialismo cultural, de Marvin Harris, para investigar el fenómeno jurídico, que encaja perfectamente en aquel marco y logra resultados fructíferos (vid. Rivaya 2007).

¿Han de interesar la antropología y la antropología del Derecho a los juristas? Sin duda, pues tanto el Derecho como la antropología son disciplinas humanísticas que tratan de ensayar respuestas sobre cuestiones fundamentales del individuo humano y la sociedad, sobre las que los juristas deben sentir curiosidad (León Carbajal 2015: 3). En lo tocante al Derecho, la antropología se hace preguntas como éstas: ¿cuándo y por qué surgió?, ¿o lo hubo siempre?; ¿son los rituales consustanciales al Derecho?; ¿por qué hay parecidos entre órdenes jurídicos que no estuvieron nunca en contacto?; ¿por qué, a la vez, hay diferencias tan

\footnotetext{
${ }^{2}$ Stefan Kirchner distingue entre antropología jurídica y derecho comparado, atribuyendo el primer conocimiento a los antropólogos y el segundo a los juristas (2015: 4-5).
} 
acusadas?; ¿por qué instituciones que fueron universales han dejado de serlo?; ¿son realmente absurdas las instituciones jurídicas o cuasijurídicas que nos parecen absurdas?; ¿en qué sentido los derechos humanos son universales?; en fin, ¿habrá Derecho siempre? Para quien busque nuevos horizontes, la antropología puede aportar originales perspectivas que el conocimiento jurídico tradicional/ convencional descuidó (Pirie 2013: 24).

La razón de ser de la antropología jurídica, por tanto, no se encuentra en una utilidad concreta, aunque eso no signifique que sea una disciplina inútil, lo que se demuestra por ejemplo analizando el papel que jugó en relación con el colonialismo, bien legitimándolo, bien desacreditándolo, y el que sigue jugando en nuestros días en relación con los pueblos indígenas. Aunque en cierto sentido la antropología jurídica es una ciencia aplicada (al estudio del Derecho), en sentido más estricto es una ciencia básica o fundamental, pues no busca ningún objetivo distinto a la obtención de conocimiento acerca del Derecho: ¿por qué hay Derecho?, ¿cuándo nació?, ¿cómo evolucionó?, etc. Así, aunque pueda interesarse por la ciencia jurídica, se distingue muy claramente de ésta, que sí es una ciencia aplicada; pretende generar buenas leyes, sentencias, etc.

Utilidad no sólo quiere decir utilidad política, pero es cierto que la antropología, como todas las ciencias sociales, inevitablemente toma opción política. A lo largo de la historia, la teoría social ha seguido dos sendas ideológicas que han configurado las dos grandes tendencias a la hora de hacer antropología y sociología del Derecho. Mientras que para unos la sociedad se comprendía como una lucha permanente, un conflicto constante, y el Derecho se concebía como un instrumento que algunos de los contendientes utilizaban con fines bélicos, los otros se fijaban en los elementos armonizadores, solidarios, que hacían posible la vida social, y así destacaban la contribución que los ordenamientos jurídicos hacían al fin de la cohesión social (Harris 1987: 404). Ambas posibilidades son legítimas y necesitan ser exploradas más allá de las afirmaciones generales que hicieron los grandes de la teoría social. Recuérdese que Marx y Engels descubrieron la voluntad de la clase hegemónica tras la mistificación del Derecho, entendido como armamento que se utilizaba en la guerra de clases (1985: 77), mientras que Durkheim dijo claramente que el orden jurídico era un instrumento que los hombres y las sociedades utilizaban "para poder vivir" (1984: 45). De esta forma, conflictualismo y armonicismo aparecen no sólo como dos grandes concepciones de la sociedad, sino también del Derecho, que así adquiere explicación (y valoración) en atención a la función que desempeña en la vida social.

Además, podríamos clasificar la antropología del Derecho con arreglo a otros criterios analíticos que también sirven para ordenar las ciencias sociales en general. Así, hay 
una antropología idealista y otra materialista, según que encuentre en los factores ideales o en los materiales la causa de los fenómenos socioculturales y, por lo que ahora nos interesa, de los jurídicos; funcionalista o estructuralista, según que se fije en el fin, el para qué del Derecho, o en su mecánica, su estructura; explicativa o hermenéutica, según que busque la causa de los fenómenos jurídicos o la comprensión de los mismos.

\section{El objeto de la antropología jurídica}

La relación entre la teoría del Derecho y la antropología jurídica es sumamente interesante. Por una parte, la antropología jurídica necesita de la teoría del Derecho, que se ocupa del concepto del Derecho, concepto que aquélla precisa para guiar su labor. Por otra, la teoría del Derecho ha de encontrar en la antropología jurídica un material muy rico para elaborar su especulación. Pero como no hay un único concepto del Derecho sino varios, tampoco hay una sino muchas teorías del Derecho y no todas experimentan el mismo interés por la antropología jurídica. Creo que en general podríamos decir que las corrientes más formalistas sienten poca o ninguna atracción por ella, mientras que a las antiformalistas les atrae $y$, en ocasiones, les llega a fascinar.

Fijémonos por ejemplo en el positivismo legalista que identificaba Derecho y ley, Derecho y regla estatal, con lo que toda la normatividad pre y extra estatal quedaba fuera de las fronteras de la geografía jurídica. Así, creo que, al menos en principio, ni los partidarios de esta concepción estatalista ven en la antropología jurídica un saber atractivo, ni a los antropólogos les resulta aquélla sugerente en medida alguna (p.e. Pospisil 1974: 22-23). Lo mismo ocurre con la famosa teoría pura del Derecho, de Hans Kelsen, que en buena medida es un ejemplo sofisticado de dicha concepción formalista, aunque hay que advertir que Kelsen sí se interesó por la antropología, leyó muchas obras clásicas de esta ciencia social, de lo que dio buena cuenta en un libro que bien se puede denominar antropológico, Society and Nature (1946), que se subtituló A Sociological Inquiry, pero que bien podría haber sido An Anthropological Inquiry. En cualquier caso, se trató de un estudio dedicado a comprender la mente del hombre primitivo, que interpretaba la naturaleza conforme al principio de retribución, lo que a los ojos de Kelsen era un error a todas luces. Así, para conseguir su objetivo, elevar una doctrina jurídica pura, se desentenderá de los primitivos, que no habrían llegado a descubrir una moderna dialéctica sin la que -a su juicio- no cabe el conocimiento jurídico, la que distingue entre el principio de causalidad y el de imputación (1946: 264-266). 
Así todo, hasta donde sé, aún resta por estudiar el concepto de Derecho primitivo en Kelsen, Derecho que coincide -nos dice- con la moral (1946: 55).

Por su parte los antropólogos parecen no sentirse a gusto con Kelsen; baste con sólo dos ejemplos para probarlo. Hoebel viene a decir que quienes se dedican a la antropología son incapaces de sentir interés por una "ciencia pura del Derecho" que no se ocupa con el Derecho real sino con un Derecho perfecto, ideal, que no existe; un "Derecho zombie" (2006: 6). Pospisil, por su parte, aun sin citarlos, reniega tanto de Kelsen como del positivismo legalista cuando repudia esa perspectiva del orden jurídico que lo ve como "un sistema legal lógicamente consistente y autónomo, en el que las distintas normas que lo integran son derivadas de otras más abstractas. Estas normas, integradas en una especie de pirámide continúa-, son fundamentadas en una norma básica o en una voluntad soberana" (1974: 275).

Pero también hay teorías jurídicas sumamente interesadas en la antropología del Derecho. El caso más claro es el del realismo jurídico norteamericano (Tuori 2017: 103), que dio lugar a una colaboración enormemente fructífera entre algunos teóricos del Derecho y algunos antropólogos; especialmente la ya apuntada entre Karl Llewellyn y E. Adamson Hoebel. Llewellyn fue el más señalado representante del llamado realismo norteamericano, para el que el Derecho se entiende como una práctica, la práctica resolutoria de los tribunales, reduciendo el valor y sentido de las normas a pautas de predicción de lo que decidirán los jueces; a él se debe la introducción del case method en los estudios antropológico jurídicos (Twining 1985: 160). En cuanto a E. Adamson Hoebel, probablemente sea suya la más clásica introducción a la antropología jurídica, The Law of Primitive Man, de 1954 (2006), en la que, además de presentar las cuestiones fundamentales de esta ciencia socio-jurídica, expuso cómo era el Derecho de los esquimales, los ifugao, los comanches, los trobiandenses y los ashanti. Amalgamando la perspectiva jurídica realista con la funcional antropológica, el jurista y el antropólogo norteamericanos escribirían juntos a principios de los cuarenta The Cheyenne Way (2002), un estudio sobre el Derecho cheyene que se olvidaba, por cierto, del genocidio que sufrió este pueblo (Nader 2005: 95). Creo que parecido interés por la antropología se observa en el movimiento denominado Critical Legal Studies, pero no tanto porque se interese por el estudio de los pueblos exóticos, cuanto porque observa como exótico el panorama estadounidense (Nader 2005: 103).

Otras concepciones del Derecho sienten idéntico interés por la nueva disciplina antropológica, como el llamado movimiento de Derecho libre, cuyos más punteros

\footnotetext{
${ }^{3}$ También parecía estarlo el realismo jurídico escandinavo. Alf Ross explicaba el funcionamiento de la institución antropológica del Tû-Tû para concluir que el pensamiento jurídico contemporáneo presentaba gran semejanza con el pensamiento mágico primitivo: 1976: 24.
} 
representantes hicieron referencias etnológicas en las páginas de sus obras principales. Así, Eugen Ehrlich encontró en el Derecho primitivo un ejemplo de aquello a lo que él quería referirse, el Derecho vivo, "la forma básica del Derecho", esto es, el orden inherente a las asociaciones humanas (1936: 36-37). Como Ehrlich, Hermann Kantorowicz también propuso un concepto amplio y rompió con la identificación habitual entre Derecho y Derecho del Estado, a la vez que declaraba que la moderna antropología se había "mostrado incapaz de descubrir sociedades, por primitivas y carentes de carácter estatal que fueran, desprovistas de Derecho y, consecuentemente, de ciertas nociones jurídicas" (1964: 44-48).

Realmente, no sólo las del Derecho libre sino todas las teorías del Derecho que bien pudiéramos denominar sociologistas utilizan a menudo un concepto más amplio del Derecho que las formalistas, a la vez que se sienten atraídas por el Derecho primitivo. En España, un caso claro es el de Ortega, que propuso una concepción jurídica de este tipo, a la vez que se quejaba de ese "vicio intelectual" que consiste en negar que existe una función social si no hay un órgano dedicado a cumplirla. "De este modo -dijo-, hasta hace poco los etnógrafos, al estudiar las sociedades más primitivas en que no existen magistraturas judiciales ni un cuerpo o individuos que legislen, juzgaban que en ellas no existía el Derecho" (1972: 218). Al contrario, toda sociedad tiene su Derecho, porque el orden jurídico es una "secreción espontánea”, "una operación espontánea de la sociedad" (1976: 38 y 226). Para los que piensan que el sintagma "Derecho estatal" constituye un pleonasmo, es decir, que no hay más Derecho que el estatal, Ortega advierte que lo que no hay es Derecho sin sociedad, pero que perfectamente puede haberlo sin Estado (1976: 223). En fin, valga el filósofo español como representante de una caudalosa corriente del pensamiento jurídico que entronca con la antropología jurídica.

Pero el teórico del Derecho de los últimos tiempos al que más debe la antropología del Derecho es -creo- H.L.A. Hart, que conocía y utilizó la literatura de este saber jurídico. Precisamente para elaborar el concepto de Derecho se sirvió de una hipótesis antropológica, del concepto Derecho primitivo. Por oposición, llegó a la conclusión de que la diferencia entre uno y otro ordenes jurídicos se hallaba en la simplicidad del segundo frente a la complejidad del primero: el Derecho primitivo o simple sólo se constituiría por reglas primarias que establecen obligaciones, mientras que el Derecho (complejo) también tendría reglas secundarias, que denomina de reconocimiento, cambio y jurisdicción; reglas que se ocupan de las primarias, que las regulan (que regulan su identificación, su creación y transformación, y su aplicación). Pero más allá de las concretas fórmulas que Hart utilizó para distinguir uno de otro, el acercamiento parecía correcto: el Derecho primitivo sería un 
Derecho simple que iría adquiriendo complejidad hasta que, llegado a cierto momento de su desarrollo, dejaría de ser primitivo para convertirse en Derecho con todos los títulos. Así, del Derecho primitivo dijo que se trataba, junto con el internacional, de un "caso dudoso" y, en otras ocasiones, lo llamó "caso marginal", "ejemplo discutible", "forma rudimentaria" y "forma simple" de Derecho, pues en él sólo están presenten algunos de los rasgos que se pueden predicar de lo que solemos denominar Derecho. Luego sería más cortante, cuando distinguió todas esas realidades que formarían parte del "mundo prejurídico", del indiscutible “mundo jurídico" (1977: 4, 19, 99, 108, 114 y 117-118). También los puntos de vista interno y externo, que popularizó Hart en referencia al Derecho, tienen origen antropológico y, además, defendió una doctrina típicamente antropológica del tipo de las que luego denominaré del patrón jurídico universal, la que llamó teoría del contenido mínimo del Derecho natural ${ }^{4}$, que describía las normas y otros elementos constantes en todo Derecho, universales, como la prohibición de matar o de robar.

Pero aparte del concepto del Derecho de los juristas teóricos, importa el que defendieron los antropólogos 5 . En este punto hay que referirse a una discusión fundamental entre los dos grandes de la antropología social británica, Bronislaw Malinowski y Alfred R. Radcliffe-Brown, polémica que constituye el punto de partida (lógico, no cronológico) de esta disciplina ${ }^{6}$.

Antes de dedicarse a la antropología, Malinowski había estudiado física y matemáticas, no Derecho, pero las reflexiones que hizo sobre este fenómeno fueron estimulantes tanto para los juristas como para los antropólogos. Realmente, a lo largo de su vida Malinowski no siempre defendió un mismo concepto de Derecho, lo que suele callarse, pues su nombre quedó vinculado con la perspectiva funcionalista y una visión difusa y abierta de lo jurídico. En su primera gran obra, el estudio sobre la familia de los aborígenes australianos, mantuvo una concepción intuitiva, conforme a la cual el Derecho era uno de los órdenes normativos de la sociedad, el que disponía de una organización de las sanciones, lo que exigía algún tipo de autoridad centralizada que, aun de forma rudimentaria, asumiera las que serían funciones jurídicas. Luego, en 1925, distinguió entre el Derecho y la moral

\footnotetext{
${ }^{4}$ Estoy persuadido de que en el origen de esta teoría de Hart se encuentra la teoría de las necesidades de Malinowski. No deja de llamar la atención que Hart cite el cásico de Piddington, "Malinowski's Theory of Needs", en referencia a la distinción entre punto de vista interno y externo (1977: 306), cuando sería más congruente que lo citara en relación a la teoría del contenido mínimo del Derecho natural.

${ }^{5}$ En la literatura antropológico jurídica es habitual que los autores dediquen parte de su obra a plantearse la cuestión del concepto de Derecho. A título de ejemplo: Hoebel 2006: 18-28; Gluckman 1978: 214-220; Pospisil 1985.

${ }^{6}$ Esa polémica se encuentra reconstruida en Rivaya 1998 y 2001. Allí se hallan todas las referencias bibliográficas que no se han podido incluir aquí.
} 
atendiendo a los juicios y castigos de que estaba provisto el primero, y al reforzamiento por la conciencia propio de la segunda. Después abandonaría esa concepción estructuralista a cambio de otra funcionalista pero, curiosamente, retornaría a la primera en sus últimas obras. En A Scientific Theory of Culture utilizó el término "policía" para referirse a la función política del grupo, exigió la existencia de una organización de la coacción y, en concreto, de tribunales, lo que le llevó a reconocer que no todas las sociedades primitivas tenían instituciones legales. Por fin en Freedom and Civilization, otra obra póstuma que apareció en New York en 1944, el Derecho quedó definitivamente vinculado con la autoridad y la sanción organizada.

En el grueso de su obra, sin embargo, Malinowski mantuvo una idea mucho más difusa del fenómeno jurídico, minimizando sus componentes estructurales y centrándose en el control social que ejerce. Tras investigar los aspectos económicos de la sociedad trobiandense, en Crime and Custom se fijó en los jurídicos. Para captarlos apuntó un método: al estudiar una realidad íntegramente, por ejemplo una canoa, habría que analizar cómo se construía, cómo se usaba y cómo se consideraba; así aparecerían por un lado los simples hechos que constituían su sociología, pero también las muy diversas normas que estaban implicadas en ellos. Mas todas esas reglas eran de diverso tipo y podían distinguirse por la manera de proteger el deber que establecían: las había religiosas, familiares, morales, propias de las buenas costumbres, jurídicas, etc. ¿Cuáles eran estas últimas? A su juicio las que se caracterizaban por dos notas: porque establecían derechos y obligaciones, y porque se hallaban respaldas por "una definida maquinaria social de poderosa fuerza obligatoria", una maquinaria basada en la reciprocidad (1991: 65-74). A la vez explicó cuál era la función del Derecho: "contener ciertas propensiones naturales, canalizar y dirigir los instintos humanos e imponer una conducta obligatoria no espontánea; con otras palabras, asegurar un tipo de cooperación basado en concesiones mutuas y en sacrificios orientados hacia un fin común" (1991: 79-80). En la introducción al libro de Hogbin, Law and Order in Polynesia, siguió los mismos derroteros: el Derecho de las sociedades primitivas debería definirse por su función, no por su forma (Hogbin 1952: LXIII). Por fin, en sus comentarios al estudio de Llewellyn y Hoebel, The Cheyenne Way, dejó claro el porqué de su concepción del Derecho. Creo que se podría decir así: los juristas solían querer distinguir el Derecho de los otros fenómenos de la cultura; Malinowski, en cambio, quería confundirlos, aunarlos, integrarlos. "El Derecho no es un fin en sí mismo - dijo-, sino un instrumento indispensable para alcanzar los fines reales, en última instancia biológicos, del obrar" (1942: 1245). 
Se puede imaginar la censura que recibió la teoría de Malinowski, que resultaba demasiado amplia, que no servía para distinguir el fenómeno jurídico del moral, que concebía el Derecho en términos tan genéricos que con solo esa palabra designaba todos o casi todos los procesos de control social. Otros pensadores, en cambio, restringían el significado de la palabra para referirse únicamente al "control social que se ejerce por medio de la aplicación sistemática de la fuerza de la sociedad políticamente organizada", como dijo un RadcliffeBrown tributario del pensamiento de Roscoe Pound, a la vez que advertía que era este uso restringido el que resultaba más conveniente para los antropólogos (1971: 212). Al contrario que Malinowski, Radcliffe-Brown mantuvo esa postura a lo largo de toda su vida. Ya en 1922 insinuó que los andamanes no tenían Derecho, pues carecían de "reglas organizadas y procedimientos", y en 1940, en el prefacio a African Political Systems, pareció vincular la existencia del Derecho verdadero a la organización política que detenta "el control y la regulación del uso de la fuerza física" (1987: XIX). Para dejarlo completamente claro, en el prefacio a African Systems of Kinship and Marriage señaló que las sanciones propias del Derecho eran las que se imponían tras el examen del caso conflictivo por un tribunal de justicia. Cuando no ocurría así, estaríamos ante reglas y sanciones morales o religiosas, pero no jurídicas. Lo que convertía un conjunto de normas en Derecho era quién y cómo lo aplicara; el juez conforme al procedimiento establecido, por tanto.

En su respuesta, Malinowski reconocerá que esa definición bien podría servir para el "Derecho civilizado", pero no para el de los pueblos primitivos, donde faltaba una organización política como la que nosotros conocemos: "tribunales, policías, códigos, jueces, fiscales". Su Derecho era consuetudinario y por eso, si el fenómeno jurídico se reducía al legal, entonces no era Derecho. Tras la comprensión de Radcliffe-Brown-decía Malinowskino sólo se hallaba una teoría simple, sino los intereses de los colonizadores, que pretendían hacer desaparecer el Derecho nativo, al negarle carácter jurídico, para imponer el suyo propio. Sin embargo, las reglas de esos pueblos son "realmente obligatorias -aseguró-, están provistas de sanción y bien pudieran incluirse en nuestros códigos coloniales" (en Hogbin 1952: XXIIIXXX).

En fin, la polémica que se produjo entre Malinowski y Radcliffe-Brown sirve aún hoy día para distinguir entre el Derecho identificado funcionalmente y el formalmente considerado (Donovan y Anderson 2003: 12). ¿Quién tenía razón? En su estudio sobre los nuer, Howell dijo con gracia que este pueblo africano, al carecer de un sistema de fuerza políticamente organizada, no tenía Derecho, pero en otro sentido no tan estricto era claro que 
no carecía de orden jurídico (1970: 22). Parecía que los dos tenían razón, por tanto. Las palabras de Karl Olivecrona, me parece, dejan resuelta la cuestión:

Estas reglas consuetudinarias de las sociedades primitivas a menudo son consideradas como su Derecho consuetudinario. Es una cuestión de terminología determinar si se puede aplicar el término Derecho a tales costumbres antes de que aparezca una organización estatal capaz de ejercer una fuerza superior sobre los individuos. En todo caso, es evidente que la situación cambia cuando aparece el Estado (1980: 105).

Quizás la de Malinowski fuera una concepción “antropológica”, dicho con todas las cautelas; una concepción que no se ciñe a un sistema racional de reglas abstractas, sino que se elabora tras la "experiencia exótica" y muestra "una multiplicidad de Derechos" (Alliot 1993: 35), cuestiones que nos llevan a la temática del pluralismo jurídico, uno de los grandes tópicos de la antropología jurídica del presente (Fikentscher 2016: 24).

El pluralismo jurídico es la teoría del Derecho preferida de un buen número de antropólogos de toda la historia de esta disciplina. Valga de ejemplo Marcel Mauss, para quien en muchas ocasiones no existe un Derecho único sino una superposición, una pluralidad de ordenamientos jurídicos: cada clan, cada tribu, poseen su Derecho, el Derecho de los hombres es distinto del de las mujeres, el de los poseedores cambia no sólo según su condición personal sino según el objeto de la posesión, etc. Lo que hoy podría parecer raro a los ojos de un jurista occidental -nos advierte Mauss- no lo era a los de quien vivió antes de la revolución, que se encontraba con múltiples Derechos, dependiendo tanto de condiciones personales y reales como de otras consideraciones (1967: 140 y 192-193). En efecto, la mejor manera para comprender de qué se trata el pluralismo jurídico es contraponiéndolo al monismo jurídico, que abarca todas aquellas teorías que afirman que sólo hay un único Derecho, el del Estado (Garzón 2013: 187), teorías que han colonizado el pensamiento jurídico de tal manera que se presentan como su sentido común, considerando "inferiores" a los demás órdenes normativos e imponiendo a quienes son partidarios del pluralismo jurídico "la carga de la prueba de definir el derecho como algo distinto al derecho estatal" (Santos 2009: 52 y 64). Frente a la convencional, se trata de una concepción alternativa y posmoderna del Derecho que afirma que el del Estado sólo es un Derecho entre otros muchos (Suárez Llanos 2018: 89-93). En fin, quienes defienden el pluralismo se preguntan: ¿por qué el Derecho del Estado se arroga el monopolio del uso de la palabra "Derecho"?, ¿se trata de una idea "científica" que ha de 
aceptarse necesariamente?, ¿por qué otras normatividades sociales claramente implantadas no pueden pretender ser calificadas de jurídicas? ¿Por qué no? (Correas 2003: 121; Santos 2009: 66).

Ahora importan menos las clasificaciones que se hacen del pluralismo jurídico (clásico y nuevo; fuerte y débil; en sentido estricto y de anclaje monista; sub y supranacional; mono y multicultural, etc.) y las lecturas políticas del mismo (según Santos, uno de sus mayores defensores, no habría nada inherentemente bueno, progresivo o emancipatorio en el pluralismo jurídico, y pone el ejemplo de la juridicidad de algunos violentos grupos paramilitares: 2009: 63); importan menos esos juicios de la literatura especializada -digoque destacar su carácter rompedor, subversivo, frente a la concepción jurídica dominante. Si rastreamos sus orígenes en la teoría del Derecho, los encontraremos en las corrientes antiformalistas de finales del siglo XIX y comienzos del XX, en el movimiento del Derecho libre, en el sociologismo y el institucionalismo, y en una abundante corriente del pensamiento jurídico que se enfrenta a un positivismo estatista, legalista, formalista, logicista, etc. (Arnaud y Fariñas 1996: 86-88). Al lado de ese pensamiento jurídico, a veces bebiendo de él, la sociología y la antropología del Derecho pretenden aportar fundamentos empíricos a las tesis pluralistas, descubrir que, en efecto, en las sociedades no opera únicamente el Derecho del Estado. Entre los antropólogos cabe citar a Bronislaw Malinowski, Leopold Pospisil, Paul Bohannan o Sally Falk Moore, entre otros muchos.

Quizás el ejemplo más conocido de estudio de un caso de pluralismo jurídico sea el de Pasárgada, favela de Rio de Janeiro donde Boaventura de Sousa Santos, en 1970, hizo trabajo de campo durante varios meses, integrándose en la vida de la comunidad, lo que le permitió, por medio de la "observación participante", descubrir el "tipo de legalidad interna, paralela a la legalidad oficial del Estado y, a veces, en contradicción con ella", que la favela había generado para "asegurar un mínimo de orden social” (2009: 131-132) ${ }^{7}$. Realmente, a la vista de los ojos de un jurista europeo, el pluralismo jurídico encontraría muchos ejemplos luminosos no sólo en esa favela de Río sino en toda América latina, desde México hasta Argentina, donde el Derecho que llevaron e impusieron los colonizadores coexistirá al lado de una rica constelación de juridicidades, a veces de forma armónica y a veces de manera desordenada y conflictiva. Al igual que ocurrió en Asia y África, el proceso descolonizador, en los siglos XIX y XX, trajo consigo que el Derecho dominante, el colonizador, fuera

\footnotetext{
7 En busca de la juridicidad de Pasárgada, partió Santos del concepto de Derecho defendido por Kantorowicz, que lo vincula a la existencia de una autoridad judicial, entendida ésta de forma amplia, sin que sea preciso aprobar una oposición; por ejemplo, según Kantorowicz, que contradice a Radcliffe-Brown, entre los habitantes de las islas Andaman existirían autoridades judiciales, los ancianos revestidos de "una especial autoridad personal" que resuelven las disputas (1964: 125-126 y 133).
} 
declarado oficial, aunque seguirán subsistiendo otros órdenes jurídicos concurrentes, los que sobrevivan a lo que ha llegado a denominarse "juridicidio" masivo. Por fin, cuando ya finalizaba el siglo XX hubo un reconocimiento constitucional del pluralismo jurídico en Colombia, Perú, Bolivia, Ecuador, Guatemala o México (Garzón 2013: 189).

Llegados a este punto, hay que dar una solución al enigma del concepto de Derecho que precisa la antropología, que así se encuentra en la tesitura de tener que adoptar alguno de los defendidos por la teoría del Derecho o de elaborar ella misma uno propio, si es que puede hacerlo. Ya hemos visto que muchos antropólogos, entre ellos Malinowski, el mejor ejemplo, tuvieron que formular un concepto del Derecho más amplio o mucho más amplio que el que habitualmente utilizan los juristas convencionales. Sin duda existen conceptos más o menos apropiados para uno u otro saber, pero resulta patente que la cuestión del concepto de Derecho no es una cuestión ni mucho menos empírica sino argumentativa, que no hay conceptos verdaderos o falsos, sino razonables o poco razonables, útiles o inútiles, adecuados o inadecuados para algo; de hecho, no hay uno sino varios conceptos del Derecho (Nino 1981). Dependiendo por qué concepto se opte, los resultados serán distintos. Por lo visto hasta aquí, suele ser habitual que los antropólogos asuman un concepto como el de Ehrlich y parecería extraño, aunque no imposible, que se decantaran por otro como el de Kelsen. En cambio, creo que no resultaría raro que hubiera antropólogos que adoptaran el concepto del Derecho de Hart para iniciar sus pesquisas ${ }^{8}$.

Pero el concepto de Derecho tampoco resuelve del todo la cuestión porque, aunque aún esté por ver en qué consiste la antropología jurídica, intuitivamente sabemos que ésta se dedica, en algún sentido, al estudio del Derecho primitivo, concepto que como es obvio no se identifica con el de Derecho; precisamente porque se trataría de un Derecho que no habría llegado a serlo del todo. El objeto de estudio de la antropología jurídica, entonces, varía según que se adopten unos u otros conceptos de Derecho y de Derecho primitivo, pero en cambio todas las antropologías jurídicas coinciden en el estudio del orden social, cómo se crea y se mantiene, y en compartir un muy amplio espacio de estudio con la antropología política. En fin, tengo para mi que el objeto de la antropología del Derecho no es tanto el estudio del Derecho o del Derecho primitivo, lo que depende de los conceptos que al respecto se mantengan, cuanto el estudio del orden social ${ }^{9}$. Repárese en que los manuales de antropología

\footnotetext{
${ }^{8}$ Así lo hace, por ejemplo, Stuart A. Schlegel, que atribuye carácter jurídico a la normatividad del pueblo tiruray, dado que se observan en ella tanto normas primarias de obligación como normas secundarias, de reconocimiento, cambio y jurisdicción, dice (1970: 156).

${ }^{9}$ Así lo plantea Hogbin en su clásico libro titulado precisamente Law and Order in Polynesia, en el que se pregunta cómo se logra la cooperación mutua y el respeto de los derechos en estos pueblos de la Polinesia. Para responder a la pregunta seguirá las indicaciones de Malinowski (1952: 78-83).
} 
social y cultural suelen dedicar un capítulo al estudio del poder y la organización social, incluyendo el Derecho; dicho de otra forma, a la ley y el orden, ése es el objeto de la antropología jurídica.

\section{El método de la antropología jurídica}

Pero pudiera ser que lo característico de esta antropología no sea sólo su objeto de estudio, el Derecho o el Derecho primitivo o incluso el orden social, cuanto el carácter externo del punto de vista del estudioso; es decir, la investigación de lo raro, lo extraño, lo otro. Entonces será antropológico casi cualquier análisis de una institución que no sea propia; incluso podrá decirse de un análisis que es más o menos antropológico, según que su objeto esté más cerca o más lejos del investigador; sea simplemente curioso o completamente insólito, a los ojos del que lo analiza. Para el caso de nuestra antropología, que estudiaría “otras formas de vida jurídica” (Geertz 1994: 214), valga el ejemplo del Derecho islámico, un Derecho sagrado cuya fuente suprema es la divinidad, que forma parte de un "sistema religioso" dirigido, en último término, a la búsqueda del ideal musulmán (Schacht 1982: 199 y 201). Tras las largas luchas que se produjeron en Europa por secularizar el ordenamiento jurídico, para la mentalidad de un jurista occidental resulta, por lo menos, chocante; más aún si se dedica al análisis de concretas instituciones de la sharía (las penales, por ejemplo). Así, el estudio que un jurista occidental hace del Derecho musulmán, desde una perspectiva externa, sería antropológico; un jurista musulmán, en cambio, podría hacer ciencia o, en su caso, sociología jurídicas, pero no antropología del Derecho.

Aparece entonces uno de los graves problemas de la antropología jurídica, que intentemos comprender una institución con nuestros conceptos y categorías, nuestros prejuicios, y así no sólo no lo consigamos sino que simplemente la distorsionemos. En fin, como apuntó Mauss, habría que estudiar las instituciones tal como son, "sin ideas preconcebidas, sin pretender equiparar los Derechos indígenas al Código civil, sin emplear la terminología europea” (1967: 177) ¿Es esto posible?

En este punto hay que hacer referencia a otro de los grandes debates de la antropología, el que se produjo entre Paul Bohannan y Max Gluckman. En 1957, Bohannan publicó su investigación sobre el Derecho de los tiv, etnia establecida en Nigeria; en 1965, apareció Politics, Law and Ritual in Tribal Society, de Gluckman, en el que contestaba duramente las necedades de Bohannan. ¿De qué discutieron? Dicho de forma resumida, se trataba de un problema tópico en la antropología, el de la traducción, que en último término 
reenvía al de la naturaleza humana. ¿Es posible que un jurista formado en una concreta cultura jurídica, con sus presupuestos o prejuicios, describa, explique y comprenda el Derecho de una cultura jurídica distinta? Volviendo al ejemplo antes apuntado: ¿puede el jurista occidental conocer sin deformar y exponer cabalmente el Derecho islámico, por ejemplo?

Paul Bohannan partió de distinguir entre lo que llamó el "sistema popular" ("folk system") y el "sistema analítico" (“analytical system”), una distinción muy semejante a la de emic-etic, que debemos a Kenneth Pike. El sistema popular es el punto de vista interno, el propio del participante en una concreta institución, ese conjunto de significados que envuelve a quien forma parte de una sociedad o cultura, mientras que el sistema analítico se refiere a los "más o menos científicos métodos" que utilizan los antropólogos y sociólogos. Curiosamente, Bohannan no pretendió utilizar un sistema analítico para estudiar el Derecho tiv, supuesto que eso pudiera hacerse, sino traducir el Derecho tiv al sistema popular occidental, comparando sus elementos con los de éste, pero "sin tratar de explicarlo en los términos de nuestro sistema de 'Derecho', lo que violentaría tanto las ideas tiv como su sistema popular" (Bohannan 1957: 4-6). Lo que constantemente hacía Bohannan era advertir al lector de la posible distorsión en que incurriría el jurista occidental al estudiar el Derecho tiv, que para empezar no estaba claro que fuera Derecho; al igual que su pensamiento jurídico, que se hallaría tan distante del nuestro que ni siquiera reconocía el Derecho divino o el Derecho natural (1957: 55 y 57) ${ }^{10}$.

Si lo que decía Bohannan podía parecer razonable, la respuesta de Max Gluckman también lo era (Rouland 1992: 168-169). ¿No entendemos que cabe la traducción entre lenguas? Entonces ¿por qué no entre lenguajes jurídicos? ¿Acaso puede observarse una realidad cultural desde ningún sitio? La pretensión de Bohannan incurría en solipsismo; no tenía en cuenta los elementos universales del Derecho (Gluckman 1978: 220 y 225). Lo que realmente ocurría era que el Derecho y el pensamiento jurídico occidentales estaban más adelantados que los de los tiv, por lo que seguramente un jurista occidental podría comprender el Derecho tiv, pero un jurista tiv no podría comprender el Derecho occidental (1978: 253).

¿Quién tenía razón? Creo que ambos, pues tan cierto es que el jurista que se acerca a un Derecho extraño tiene que ser consciente de que no es el suyo propio y, por tanto, no tratar

\footnotetext{
${ }^{10}$ Curiosamente, Margaret Mead vino a hacer antropología del Derecho natural, del que afirmó que era universal pero no porque sus contenidos lo fueran, sino porque en todos los sitios se reconocía, aunque fuera con contenidos diversos. Así todo, Mead decía que las similitudes culturales eran tan persistentes que sólo podían ser explicadas por la unidad del género humano. En concreto, era normal que hubiera semejanzas entre las culturas, porque todas ellas se integraban dentro del sistema de supervivencia de la especie. Por lo que toca al Derecho natural, no el de cada pueblo sino otro constituido por preceptos y principios que todo orden jurídico necesariamente acogía, señaló la universalidad de tres instituciones de enorme importancia: el homicidio, el incesto y la propiedad privada (1961: 51-54).
} 
de violentarlo con sus conceptos, como que tiene que ser posible la traducción de un ordenamiento a otro, por más que siempre sea imperfecta, dado que la tarea de comprender y traducir no es mecánica sino artesanal. Por eso se ha dicho que la perspectiva ideal es la que integra todas, la del participante y la del observador: primero ha de conseguirse adoptar el punto de vista del nativo, de quien forma parte de una sociedad o cultura, para luego volver a asumir la perspectiva externa del científico distanciado. La labor del etnógrafo se vuelve hercúlea; si quiere comprender ha de ser capaz de mirar desde dentro y desde afuera; de cerca y de lejos. La antropología jurídica perfecta sería la que pudiera hacer que sus investigadores se integraran en un concreto pueblo y asumieran su Derecho y, acto seguido, se alejaran tanto de él que fueran capaces de verlo como un minúsculo mecanismo dentro de un entramado gigante. Pero no siempre se puede, obviamente. A veces el antropólogo se convierte en un historiador, en el sentido de que se enfrenta a realidades que ya no existen. El Derecho azteca, tan sorprendente en muchos sentidos (León Carbajal 2015), podría ser objeto de estudio de un antropólogo del Derecho, pero desde luego ya no podría llevar a cabo una inmersión en la sociedad azteca clásica. En fin, en la medida de lo posible, el etnógrafo utilizaría primero el microscopio y, luego, el antropólogo se serviría del telescopio. No extraña que las teorías antropológicas del Derecho sean teorías macrosociológicas que tienen especialmente en cuenta la tradición doctrinal de la antropología social y cultural.

Esta distinción de perspectivas también resulta muy interesante para la teoría del Derecho convencional. La dialéctica dentro/ fuera la popularizó Hart en referencia a las normas, que tienen un aspecto interno y otro externo, y que se pueden observar desde dentro y desde fuera, aunque sólo desde dentro se captaría lo propio de ellas, su normatividad, ya que una perspectiva completamente externa sería ciega para verla. La antropología aporta también otras perspectivas que resultan de sumo interés para el estudio del Derecho. Nadie como Tylor se refirió tan claramente a la distinción cerca/ lejos, que trae consigo percepciones completamente diferentes de la misma realidad:

cuando desde una montaña miramos un ejército, olvidamos al soldado individual, al que, en realidad, apenas podemos distinguir en la gran masa, mientras vemos cada regimiento como un cuerpo organizado, que se dispersa o que se concentra, que avanza o que retrocede (1977: 27).

Así resulta que las normas se pueden ver desde dentro y desde afuera; observadas desde afuera, la distancia que separa al sujeto del objeto puede ser mayor o menor y, por 
tanto, pueden ser vistas desde más o menos cerca y desde más o menos lejos, siendo distinto en cada caso el resultado de la contemplación y el conocimiento que propicia. Las teorías antropológicas o macrosociológicas del Derecho pueden sentir interés por y utilizar el punto de vista interno y el externo más o menos cercano, pero precisamente por su carácter macro necesitan mirar desde un lugar lo más alejado posible, para así llegar a elaborar teorías generales. Refiriéndose al Derecho precisamente, Lévi-Strauss señalaba el necesario interés que el antropólogo debía sentir por la ciencia del Derecho, pero advertía que la antropología lo analizaba "en sus manifestaciones más lejanas" o "desde la perspectiva de su expresión más general" (1995: 27). Valga el ejemplo del patriarcado, interesante para el antropólogo y para el jurista, como demostraron Bachofen, en uno de los primeros grandes clásicos de este tipo de literatura, Das Mutterrecht, y Maine, en otro de los principales clásicos del género, Ancient Law, curiosamente publicados ambos el mismo año, 1861, pero manteniendo tesis enfrentadas. El antropólogo constatará que gran número de sociedades humanas son patriarcales y buscará explicaciones del dato; el jurista se fijará en que gran número de normas del Derecho y del Derecho primitivo en su caso están inspiradas por un principio que relega a la mujer a un lugar secundario. El antropólogo encontrará buenos ejemplos para su estudio en el Derecho; el jurista hallará una explicación global del fenómeno, que incluye el jurídico, en la teoría de corte antropológico que elabore aquél.

Llegados a este punto, se observa que la ubicación topográfica resulta crucial para el conocimiento del Derecho y lo clasifica. Por lo que ahora más nos interesa, nos permite distinguir entre diversas variedades dentro de la antropología jurídica, utilizada la expresión en un amplio sentido y siguiendo la clasificación ya clásica de la antropología que tomo de Lévi-Straus (1995:50): etnografía, etnología y antropología, ahora jurídicas. La primera mira desde cerca, incluso desde dentro; la segunda, desde lejos; la tercera, desde lejísimos. Así, la etnografía jurídica consistiría en la observación y análisis directo del Derecho primitivo o del Derecho extraño, el trabajo de campo; la etnología del Derecho realizaría la labor comparativa entre todos los órdenes jurídicos (no extraña que Henry Sumner Maine denominara “jurisprudencia comparada” a la nueva ciencia jurídico social: 1993: 87); por fin, la gran antropología, macrohistoria o sociología total del Derecho integraría el estudio de todos los órdenes jurídicos con el fin de obtener conclusiones válidas universalmente, tanto diacrónica como sincrónicamente; sería un conocimiento completo del Derecho, desde dentro y desde afuera, de cerca y de lejos, todo a un tiempo (vid. Rouland 1992: 120; Fikentscher 2016: 12); daría lugar a las que podríamos denominar teorías macrosociológicas del Derecho (Varga 1988). 


\section{Ubi societas ibi ius?}

Una de las preguntas propias de la antropología jurídica es la que se refiere a la existencia del Derecho. ¿Efectivamente donde hay sociedad hay derecho? Ubi societas, ibi ius? Preguntado de otra manera, ¿forma parte el Derecho de las realidades culturales universales? ¿Qué dicen al respecto las teorías del patrón cultural universal? Porque que un rasgo sea universal puede querer decir que es natural; de hecho se entiende que los rasgos naturales son universales. Pero por más que la expresión Derecho natural sea tradicional, el Derecho no es natural; el Derecho es cultura. ¿Existen rasgos culturales, no naturales, universales? Si se contesta afirmativamente, ¿es el Derecho uno de ellos? A esta pregunta se le da respuesta desde la antropología jurídica, disciplina para la que constituye un interrogante muy fructífero, si bien la teoría del Derecho también resulta concernida porque en buena medida, otra vez, la contestación depende del concepto de Derecho que se utilice ${ }^{11}$. No son pocos los antropólogos que, defendiendo una perspectiva amplia sobre el Derecho, piensan que efectivamente se trata de un rasgo universal. Si distinguimos entre pluralismo y monismo jurídicos, los partidarios del primero pensarían que el Derecho aparece en todas las sociedades humanas, mientras que los defensores del monismo jurídico creerían que sólo existe en las sociedades estatales (Santos 2009: 52 ss.). Ya hemos hecho referencia a la clásica polémica entre Malinowski, que identifica el Derecho funcionalmente, convirtiéndolo en un universal, y Radcliffe-Brown, que para definirlo atiende a su estructura, a su forma, con lo que ni muchos menos estaría presente en todas las sociedades (Donovan y Anderson 2003: 12). En fin, si acudimos a la clásica definición de cultura, de Tylor, lo incluía, lo que significa que allá donde hay cultura, sociedad humana, hay Derecho ${ }^{12}$ :

Tomada en su amplio sentido etnográfico, es ese complejo conjunto que incluye el conocimiento, las creencias, las artes, la moral, las leyes, las costumbres y cualesquiera otras aptitudes y hábitos adquiridos por el hombre como miembro de la sociedad (1977: 19).

\footnotetext{
${ }^{11}$ Por supuesto, si se incurre en etnocentrismo y el Derecho se identifica con el Derecho occidental, entonces no es universal (Sacco 2007: 19). ¿O acaso el Derecho es un invento de los romanos? (Schiavone 2009).

${ }^{12}$ Esa comprensión es ya clásica y sigue siendo postulada hoy día. Donald E. Brown, por ejemplo, defiende que el Derecho tiene un carácter universal, se encuentra en todas las sociedades humanas: reglas que establecen criterios de pertenencia, derechos y obligaciones, proscripciones de la violencia y sanciones consistentes, al menos, en la exclusión social (1991: 138). Algo parecido a lo que ya había expresado Hart en la teoría del contenido mínimo del Derecho natural (1977: 239-246).
} 
Pero Tylor era un evolucionista y, por tanto, la definición tiene algo de enigmática. ¿Desde cuándo existe? Porque hay cultura desde el momento en que se produjo la primera transmisión de un conocimiento por medio de la enseñanza/ aprendizaje, pero ¿ya había Derecho entonces? ¿O surge más bien en el camino que va de la aparición de esos primeros gérmenes culturales hasta el momento actual? Efectivamente, el mismo Tylor habría de reconocer que hubo un tiempo en que no existió Derecho, cuando sólo había la venganza, y que iría "apareciendo gradualmente" (1987: 489), lo que parece que asimismo reconocerán Morgan y Spencer.

El caso de Marx también resulta interesante porque en la cita clásica en la que ordena la sociedad para luego aplicar el principio del determinismo económico se refiere expresamente al Derecho:

El conjunto de estas relaciones de producción constituye la estructura económica de la sociedad, la base real sobre la cual se eleva la superestructura jurídica y política y a la que corresponden formas sociales determinadas de conciencia. El modo de producción de la vida material condiciona el proceso de vida social, política e intelectual en general. No es la conciencia de los hombres la que determina la realidad; por el contrario, la realidad social es la que determina su conciencia [...] El cambio que se ha producido en la base económica transforma más o menos lenta o rápidamente toda la colosal superestructura (2004: XXXI).

¿Efectivamente postuló el marxismo que toda sociedad tiene Derecho? No lo creo, al menos si entendemos por Derecho lo que convencionalmente se entiende por tal. En El origen de la familia, de la propiedad privada y el Estado, Engels hizo una descripción de la evolución de la humanidad, para lo que utilizó, además de la periodificación de Morgan, la distinción entre sociedad gentilicia y estatal; contando aquélla con la sola opinión pública como medio coercitivo, mientras que ésta utilizará ya la forma legal (1988: 171-172). Evolucionistas como Marx y Engels no suelen creer que el Derecho exista desde el inicio de los tiempos; al contrario, es normal que vean su nacimiento en un determinado momento de esa evolución. Entonces, la expresión "superestructura jurídica y política" no habría que traducirla como "Derecho y Estado" sino, más ampliamente, como "organización social”, lo que no requiere necesariamente ni del Derecho ni del Estado, en sentido estricto. De hecho, de aquél se podría predicar lo mismo que Engels predicó de éste, con lo que la cita pasaría a decir: "el Derecho 
no ha existido eternamente. Ha habido sociedades que se las arreglaron sin él, que no tuvieron la menor noción del Derecho ni de su Poder. Al llegar a cierta fase de desarrollo económico que estaba ligada necesariamente a la división de la sociedad en clases, esta división hizo del Derecho una necesidad" (1988: 177).

Pero quien primero utilizó la expresión de "patrón cultural universal" (universal culture pattern) fue Clark Wissler para referirse a los procesos y estructuras constantes que se daban en todas las culturas, entendiendo éstas como los modos de vida de los pueblos. La lista que elaboró de rasgos culturales comunes fue incompleta y confusa pero, por lo que ahora nos interesa, incluyó el Derecho bajo la expresión de "procedimientos judiciales y legales" (1965: 73-97). Como había hecho Marx, lo colocó al lado del fenómeno político.

Posteriormente, otros antropólogos mantuvieron la tesis conforme a la cual el jurídico sería un fenómeno universal; por ejemplo Murdock, el campeón del análisis comparativo, que incluyó las leyes entre los rasgos universales de la cultura (1987: 86). Las categorías universales de Murdock, sin embargo, tenían en cada cultura un contenido específico. En todas existían derechos de propiedad, pongo por caso, pero en ninguna eran iguales. En todas había restricciones sexuales, pero nunca eran exactamente las mismas. Lo mismo cabría decir de las leyes, que tendrían distintos contenidos; aunque lo que llama la atención es que dijera de ellas que eran universales, lo que significaría que el Derecho es un universal de la cultura; claro que quizás haya quien piense que se trataba de un uso excesivo del término, porque en otro lugar afirmaba que el hipotético Derecho de los tasmanianos, pueblo ya desaparecido, era completamente rudimentario; los semang de Malaya carecían de algo que se pareciera a las leyes formales; los kazacos del Asia central desconocían cualquier formalidad jurídica, etc. $(1975: 19,86,128)$.

Hay que advertir que los rasgos no eran tanto universales per se, cuanto por obra del investigador que, con buen criterio, los agrupaba bajo una misma rúbrica: derechos de propiedad o restricciones sexuales o leyes, por ejemplo. Entonces, el patrón cultural universal era el resultado de un proceso abstractivo que culminaba en un concepto relativamente formal. Entre todos los productos culturales, o al menos entre muchos de ellos, había similitudes y diferencias, y se podía optar por poner el acento en unas o en otras. Ahora bien, si se reparaba en las semejanzas, habría que interesarse por su razón de ser y ésta sólo se podía encontrar - dijo- "en la naturaleza biológica y psicológica fundamental del hombre y en las condiciones universales de la existencia humana" (1987: 87).

Pero el mayor defensor de la universalidad del fenómeno jurídico, como ya sabemos, fue Malinowski. Utilizando un concepto amplísimo del Derecho, hay que suponer que estaba 
en todos lados. Pero ¿realmente es así?, ¿efectivamente donde hay sociedad hay Derecho? En concreto: ¿tenían orden jurídico los primeros grupos de homínidos o, en concreto, de neandertales o sólo de sapiens? Difícilmente se puede creer eso aunque, obviamente, otra vez dependemos del concepto de Derecho que utilicemos, lo que no obsta para que todos admitamos que el Derecho se ha convertido en un fenómeno universal o quasiuniversal. Para unos, siempre lo habría sido; para otros, que hoy día exista en todas o en casi todas partes no significa que haya existido siempre. Para estos últimos, las dos preguntas fundamentales de la antropología jurídica serían: ¿cuándo surgió el Derecho? y ¿por qué se convirtió en universal?

Se suele entender por antropología jurídica el estudio del Derecho primitivo pero, como el de Derecho a secas, incluso más que éste, el concepto de Derecho primitivo resulta sumamente problemático debido a su carácter difuso. En efecto, el tiempo del Derecho primitivo abarcaría un período muy amplio de la (pre)historia de la humanidad marcado por dos fronteras: abarcaría desde el que podríamos llamar primer orden jurídico, el más simple de todos, hasta otro que ya estaría al lado del Derecho sin más, dando paso a éste. Dos fronteras, por tanto: la que separa el no Derecho del Derecho primitivo, y la que distingue el Derecho primitivo del Derecho.

En cuanto a la primera frontera, ¿en qué momento de la historia de la humanidad surgió el Derecho? Desde una perspectiva evolucionista difícilmente se puede creer que con la presencia del homo sapiens apareció el primer Derecho, sino que más bien parece que aquel sapiens tuvo que desarrollarse hasta llegar a un estadio en que surgió un fenómeno cultural tan singular y característico como el jurídico ${ }^{13}$. Porque quizás el nacimiento de la cultura se

13 En un sentido distinto, Ribas 2015: 44, para quien el lenguaje y el Derecho son los rasgos que "singularizan al ser humano dentro del reino animal".

\section{LEGAL ANTHROPOLOGY}

Abstract

Legal anthropology is that part of social or cultural anthropology that is dedicated to the study, comparative and far-reaching, of social organization and, specifically, of Law. A fundamental issue for this anthropology is that of the concept of Law, as it needs to define its purpose. In this regard, the controversy between Malinowski and Radcliffe-Brown is classic, as classic is the controversy between Gluckman and Bohannan, about the method of legal anthropology. Two nuclear themes of the anthropology of Law are that of its 
universality and that of both universal and particular features of legal orders. At present, the comparative study of human rights makes this anthropology indispensable.

Keywords: Legal anthropology; concept of law; primitive right; legal anthropological method; universality of law; universal features of law; legal rituals; human rights.

\section{BIBLIOGRAFÍA}

- Alliot, M. 1993: "Anthropologie juridique”. En Dictionnaire encyclopédique de théorie et de sociologie du droit, dir. Arnaud, A.J. Paris: LGDJ.

- $\quad$ Arnaud, A.-J. y Fariñas, M. J. 1996: Sistemas jurídicos: Elementos para un análisis sociológico. Madrid: Universidad Carlos III y BOE.

- $\quad$ Assier- Andrieu, L. 1999: "Il tempo e il diritto dell'identità collettiva. Il destino antropologico del concetto di consuetudine". Sociologia del Diritto XXVI-3: 15.

- Bachofen, J. J., [1861] 1987: El matriarcado. Una investigación sobre la ginecocracia en el mundo antiguo según su naturaleza religiosa y jurídica. Madrid: Akal.

- $\quad$ Benedict, R. [1934] 1989: El hombre y la cultura. Barcelona: Edhasa.

- Boas, F. [1928] 1962: Anthropology and Modern Life. New York: Dover Publications.

- $\quad$ Bohannan, P. 1957: Justice and Judgment among the Tiv. London: Oxford University Press. Cátedra.

Bottéro, J. [1987] 2004: Mesopotamia. La escritura, la razón y los dioses. Madrid:

- $\quad$ Brown, D. E. 1991: Human Universals. New York etc.: McGraw-Hill, Inc.

- $\quad$ Correas, O. 2003: Pluralismo jurídico, alternatividad y Derecho indígena. México: Fontamara.

- $\quad$ Davitt, Th. E. [1968] 1978: The Basic Values in Law. A Study of the Ethnico-legal Implications of Psychology and Anthropology.

- Diaz Cruz, R. 1998: Archipiélago de rituales. Teorías antropológicas del ritual. Barcelona: Anthropos y UAM.

- $\quad$ Donovan, J.M y Anderson, H.E. 2003: Anthropology \& Law. New York: Berghahn.

- $\quad$ Durkheim, E. [1895] 1984: La reglas del método sociológico. Madrid: Morata.

- $\quad$ Durkheim, E. [1912] 1993: Las formas elementales de la vida religiosa. Madrid: Alianza Editorial.

- Ehrlich, E. 1936: Fundamental Principles of the Sociology of Law. Cambridge, Massachusetts: Harvard University Press.

- $\quad$ Engels, F. [1884] 1988: El origen de la familia, la propiedad privada y el Estado. Madrid: Ediciones Endymión.

- $\quad$ Ferrari, V. 2000: Acción jurídica y sistema normativo. Introducción a la sociología del Derecho, Instituto de Derecho Humanos Bartolomé de las Casas y Dykinson, Madrid.

- $\quad$ Fikentscher, W. 2016: Law and Anthropology. München: C.H. Beck.

- $\quad$ Garapon, A. 2000: Bien juger. Essai sur le rituel judiciaire. Paris: Odile Jacob.

- Garzón López, P. 2013: "Pluralismo jurídico". En Eunomía. Revista en Cultura de la Legalidad 5: 186-193.

- $\quad$ Geertz, C. [1983] 1994: Conocimiento local. Barcelona: Paidós. 
- $\quad$ Gluckman, M. [1965] 1978: Política, Derecho y ritual en la sociedad tribal. Madrid: Akal.

- $\quad$ Goody, J 1990: La lógica de la escritura y la organización de la sociedad. Madrid: Alianza Editorial.

- $\quad$ Harris, M. [1968] 1987: El desarrollo de la teoría antropológica. Una historia de las teorías de la cultura. Madrid: Siglo XXI.

- Harris, M. 1994: Bueno para comer. Enigmas de alimentación y cultura. Madrid: Alianza Editorial y Ediciones del Prado.

- $\quad$ Hart, H.L.A. [1961] 1977: El concepto de Derecho. Buenos Aires: Abeledo-Perrot.

- $\quad$ Hoebel, E. A. [1954] 2006: The Law of Primitive Man. A Study in Comparative Legal Dynamics. Cambridge, Massachusetts: Harvard University Press.

- $\quad$ Hogbin, H. I. [1934] 1952: Law and Order in Polynesia. A Study of Primitive Legal Institutions. London: Christophers.

- $\quad$ Howell, P. P. [1954] 1970: A Manual of Nuer Law. Glasgow etc.: International African Institute \& Oxford University Press. Occidente.

Kantorowicz, H. [1958] 1964: La definición del Derecho. Madrid: Revista de

- $\quad$ Kelsen, H. 1946: Society and Nature. A Sociological Inquiry. London: Routledge \& Kegan Paul.

- Kelsen, H. [1953] 1981: Teoría pura del Derecho. Introducción a la ciencia del Derecho. Buenos Aires: Editorial Universitaria de Buenos Aires.

- Kirchner, S. 2015: Researching Indigenous Law. Legal Anthropology or Comparative Law? Munich: GRIN.

- $\quad$ Kramer, S. N. 1958: La historia empieza en Sumer. Barcelona: Aymá.

- $\quad$ Krotz, E., ed., 2002: Antropología jurídica: perspectivas socioculturales en el estudio del Derecho. Barcelona: Anthropos y UNAM.

- $\quad$ León Carbajal, F. [1864] 2015: Discurso sobre la legislación de los antiguos mexicanos. Ciudad de México: INACIPE.

- $\quad$ Lévi-Strauss, C. [1949] 1991: Las estructuras elementales del parentesco. Barcelona: Paidós.

- $\quad$ Lévi-Strauss, C. [1958] 1995: Antropología estructural. Barcelona: Paidós.

- $\quad$ Liverani, M., y Mora, C., eds. 2008: I diritti del mondo cuneiforme (Mesopotamia e regioni adiacenti ca. 2500-500 a.C.). Pavia: IUSS Press.

- $\quad$ Llewellyn, K. N. y Hoebel, E. A. [1941] 2002: The Cheyenne Way. Conflict and Case Law in Primitive Jurisprudence. New York: William S. Hein \& Co., Inc.

- $\quad$ Maine, H.S. [1861] 1993: El Derecho antiguo. Madrid: Civitas.

- Malinowski, B. 1942: "A New Instrument for the Interpretation of Law. Especially Primitive". The Yale Law Journal 51: 1237-1254.

- $\quad$ Malinowski, B. [1926] 1991: Crimen y costumbre en la sociedad salvaje. Barcelona: Ariel.

- $\quad$ McLennan, J. F. [1886] 2018: Studies in Ancient History. London: Forgotten Books.

- $\quad$ Marx, K. [1859] 2004: Contribución a la crítica de la economía política. Granada: Comares.

- $\quad$ Marx, K. y Engels, F. [1848] 1985: El manifiesto comunista. Madrid: Alhambra.

- $\quad$ Mauss, M. 1967: Manuel d'etnographie. Paris: Editions Payot.

- $\quad$ Mead, M. 1961: "Some Anthropological Considerations Concerning Natural Law". Natural Law Forum 6: 51-64.

- $\quad$ Molina, M, ed., 2000: La ley más antigua. Textos legales sumerios. Barcelona: Trotta y Universitat de Barcelona.

- $\quad$ Morgan, L. H. [1877] 1975: La sociedad primitiva. Madrid: Ayuso. 
- $\quad$ Murdock, G. P. [1934] 1975: Nuestros contemporáneos primitivos. México: FCE.

- Murdock, G. P. [1965] 1987: Cultura y sociedad. 24 ensayos. México: Fondo de Cultura Económica.

- $\quad$ Nader, L. 2005: The life of the Law. Anthropological Projects. Berkeley: University of California Press.

- $\quad$ Nino, C. S. 1981: "Los conceptos de Derecho". Crítica 13: 29-52.

- $\quad$ Olivecrona, K. [1939] 1980: El derecho como hecho. Barcelona: Labor.

- $\quad$ Ortega y Gasset, J. [1957] 1972: El hombre y la gente. Madrid: Espasa-Calpe.

- $\quad$ Ortega y Gasset, J. [1929] 1976: La rebelion de las masas. Madrid: Espasa-Calpe.

- $\quad$ Pirie, F. 2013: The Anthropology of Law. Oxford: Oxford University Press.

- $\quad$ Pospisil, L. [1971] 1974: Anthropology of Law. A Comparative Theory. New Haven:

HRAF Press.

- $\quad$ Pospisil, L. 1985: "Law”. Quaderni Fiorentini per la storia del pensiero giuridico moderno 14: 23-75.

- $\quad$ Radcliffe-Brown, A. R. [1952] 1971: Structure and Function in Primitive Society. London: Cohen \& West.

- $\quad$ Radcliffe-Brown, A. R. [1940] 1987: "Preface”. In Fortes, M. \& Evans-Pritchard, E. E. [1940] 1987: African Political Systems. London etc.: KPI.

- $\quad$ Ribas Alba, J. M. 2015: Prehistoria del Derecho. Córdoba: Almuzara.

- Rivaya, B. 1998: "Una teoría científica del Derecho. El pensamiento jurídico de Bronislaw Malinowski”. Sociologia del Diritto 25: 29-58.

- $\quad$ Rivaya, B. 2001: "Estructura y función en el Derecho primitivo. El pensamiento jurídico de Radcliffe-Brown". Sociologia del Diritto 28-2: 45-74.

- $\quad$ Rivaya, B. 2007: El materialismo jurídico. La presunta teoría del Derecho de Marvin Harris. Madrid: Dykinson.

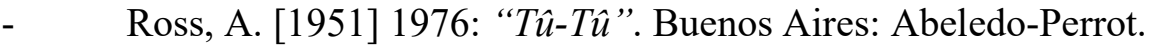

- $\quad$ Rouland, N. [1988] 1992: Antropologia giuridica. Milano: Giufrè Editore.

- $\quad$ Sacco, R. 2007: Antropologia Giuridica. Contributo ad una macrostoria del Diritto. Bologna: Il Mulino.

- $\quad$ Sanmartín, J, ed., 1999: Códigos legales de tradición babilónica. Barcelona: Trotta y Universitat de Barcelona.

- $\quad$ Santos, B. de S. 2009: Sociología jurídica crítica. Para un nuevo sentido común en el Derecho. Madrid: Trotta.

- $\quad$ Schacht, J. 1982: An Introduction to Islamic Law. Hong Kong: Clarendon Press.

- $\quad$ Schiavone, A. 2009: Ius. La invención del Derecho en Occidente. Buenos Aires: Adriana Hidalgo.

- $\quad$ Schlegel, S. A. 1970: Tiruray Justice. Traditional Tiruray Law and Morality. Berkeley etc.: University of California Press.

- $\quad$ Suárez Llanos, L. 2018: El posmodernismo jurídico y la filosofía del Derecho. Valencia: tirant lo blanch.

- $\quad$ Tolstoi, L. [1899] 1992: Resurrección. Barcelona: Planeta.

- Tuori, K. 2017: Lawyers and Savages. Ancient History and Legal Realism in the Making of Legal Anthropology. London: Routledge.

- Twining, W. [1973] 1985: Karl Llewellyn and the Realist Movement. London: Weindenfeld and Nicolson.

- $\quad$ Tylor, E. B. [1871] 1977: Cultura primitiva. Madrid: Ayuso.

- Tylor, E. B. [1881] 1987: Antropología. Introducción al estudio del hombre y la civilización. Barcelona: Editorial Alta Fulla.

- Varga, C. 1988: "Teorías macrosociológicas del Derecho", Anuario de Filosofía del Derecho V: 23-53. 
produjo con el surgimiento de una norma (según Lévi-Strauss la que prohibía el incesto y obligaba, por tanto, a la exogamia: 1991: 42), pero no de una norma jurídica.

En cuanto al despegue del Derecho primitivo y el nacimiento del Derecho bien podría señalarse un lugar y un tiempo determinados: Mesopotamia, en el cercano oriente, en torno al 3500 antes de Cristo. El origen del Derecho estaría vinculado a la invención de la escritura, al aumento de la población, de la producción agrícola, al auge del comercio, a la creación de las ciudades, a la constitución del Estado, con su administración y su ejército, etc. En fin, si la historia empieza en Sumer (Kramer, 1958) también la del Derecho comenzaría en Súmer.

La escritura puede servir como criterio para diferenciar el Derecho del no-Derecho, y entonces el primer orden jurídico habría sido cuneiforme (Liverani y Mora 2008); o para diferenciar entre un Derecho escrito y otro no escrito, ágrafo (Goody 1990: 162). La clásica distinción, que debemos a Roscoe Pound, entre Law in Books y Law in Action, requiere de la escritura; sin ella no hay Derecho en los libros; todo es Derecho en acción (Nader 2005: 91). La escritura, por tanto, ese sistema de signos que representa un lenguaje articulado, que nació vinculada a la administración y el comercio, resulta fundamental para el fenómeno jurídico. Por otra parte, quizás sea cierto que el código de Hammurabi y otros anteriores a él no fueran códigos, y que las leyes no eran leyes en el sentido en que nosotros las entendemos, y que el Derecho mesopotámico seguía siendo básicamente consuetudinario (Bottero 2004: 187-219; Molina 2000: 9-37; Sanmartín 1999: 42-51); así todo estaba surgiendo una nueva realidad a la que muchos van a llamar Derecho.

La clasificación de la historia de la humanidad desde el punto de vista de la aparición del Derecho, en un sentido antropológico, no tiene que resultar singular, sino que valdrían las ya elaboradas atendiendo a otros criterios. En concreto, la clasificación de Morgan me sigue pareciendo válida, ahora para distinguir entre el no Derecho, el Derecho primitivo y el Derecho sin más. Así, en las sociedades cazadoras-recolectoras, lo que viene a ser el "salvajismo", en términos de Morgan, no habría Derecho; mientras que las sociedades tribales, agrícolas y ganaderas, preestatales o protoestatales, propias del período que Morgan llama "barbarie", habría un Derecho primitivo; por fin, en las sociedades estatales, a las que se refiere Morgan con el término "civilización”, existiría esa invención cultural tan peculiar que según muchos es el Derecho.

Admitida esa u otra clasificación cronológica, incluso admitida una concepción más o menos amplia del Derecho, de lo que parece que no cabe duda es de que se ha

Wissler, C. [1923] 1965: Man and Culture. New York: Thomas Y. Crowell. 
universalizado. ¿Por qué? En principio cabría ensayar respuestas diversas: el Derecho podría surgir de la creación independiente o podría deberse a la difusión (Sacco 2007: 54). No cabe duda de que en el ámbito jurídico la difusión ha jugado históricamente un importante papel; baste con referirse al ejemplo evidente del Derecho romano; muchas instituciones han sido copiadas por unos ordenamientos de otros. Pero el Derecho, ya sea entendido en un sentido amplio omniabarcador de toda o casi toda normatividad social, o en un sentido restringido que lo identifica con el Derecho del Estado, habría surgido de forma independiente; si no en todos, al menos en algunos casos.

\section{Las teorías de los patrones jurídicos universal y particular}

La cuestión del patrón cultural universal, la de los rasgos universales de la cultura y la de si entre ellos se encuentra el Derecho, nos lleva a la otra del "patrón jurídico universal", la de los rasgos universales del fenómeno jurídico, si bien las teorías que se dedican a ese cometido a veces describen las normas universales, lo que podríamos denominar Ius Gentium; en otras ocasiones, de manera más amplia, las características comunes a todo Derecho, incluido el primitivo; en otras, por fin, las dimensiones que se repiten en uno y otro orden jurídico. El patrón jurídico universal es el resultado de la labor comparativa propia de la antropología del Derecho. Pero la misma labor comparativa elabora los "patrones jurídicos particulares", cuando se fija no en los parecidos sino en las diferencias entre los órdenes jurídicos. En cierta forma se trata de la clásica distinción entre Derecho natural y Derecho de gentes, y Derecho civil; aquéllos expresan lo común, éste lo particular (Maine 1993: 41). En cualquier caso, una pregunta significativa que tiene que responder la antropología jurídica es la de las razones tanto de las semejanzas como de las diferencias entre los distintos Derechos.

El patrón jurídico universal contendría normas o principios normativos de entre los cuales la proscripción del homicidio (y, más en general, de las agresiones) sería el mejor ejemplo, dado que los seres humanos suelen querer seguir viviendo y ninguna sociedad puede permitir que los brotes de violencia sean demasiado frecuentes. El "no matarás" se nos revela como una norma (un fenómeno cultural, por tanto) universal de conducta, vinculada incluso con exigencias biológicas del organismo humano, aunque su universalidad quizás se explique mejor por la evitación de una situación social alarmante. Pueden surgir dudas respecto a la universalidad de la prohibición del homicidio, dado que, utilizando palabras de Boas, "a veces asesinar no es crimen sino virtud" (1962: 125); dado que en muchas ocasiones se permite matar, es decir, que matar no estaría prohibido siempre. Realmente no existe pueblo alguno 
en el que no esté prohibido matar, por más que las excepciones a la regla $\mathrm{o}$, en otros términos, las reglas para el quebrantamiento de la regla que prohíbe matar puedan ser variadas. La proscripción del homicidio es una regla general, pero la institución del homicidio, dar muerte ilegítimamente a otro, abarca también un conjunto de reglas particulares que establecen cuándo matar es legítimo. Esa distinción es conocida por todas las sociedades humanas, pero los criterios que utilizan para diferenciar entre muertes legítimas e ilegítimas son distintos (Davitt 1987: 43). En cualquier caso, no extraña que tanto antropólogos como juristas sean conscientes de que estamos ante la primera o una de las primeras normas de la sociedad humana. Según Harris, por ejemplo, "el tabú contra el asesinato y consumo de los propios parientes constituye la condición previa fundamental de la convivencia" (1994: 228). Según Kelsen, "el incesto y el homicidio en el interior del grupo son, sin duda, los crímenes más antiguos" (1981:21).

En cuanto al sistema económico, a la producción y distribución de los recursos, tampoco puede haber orden jurídico alguno que no ofrezca una normativa al respecto. Es cierto que las posibilidades son muy variadas, pero existen ciertos límites que las normas jurídicas no pueden vulnerar. Precisamente porque todos los pueblos poseen ciertos productos de los que depende su supervivencia, el Derecho ha de protegerlos de la destrucción, el saqueo y la rapiña. Que los recursos, escasos por principio, deben protegerse, resulta norma tan básica que no es extraño el asombro de Franz Boas, el padre del particularismo histórico, al descubrir la práctica de los kwakiutl, de la isla de Vancouver, llamada potlach. Los potlach eran fiestas rituales en las que los nativos destruían y se regalaban toda clase de riqueza, y lo hacían de forma tan desmedida que daba la impresión de ser un comportamiento sin sentido, absurdo. Pero por una parte, semejantes juergas tenían sus límites e, incluso, podían interpretarse como instituciones con un marcado carácter económico, no antieconómico, parecidas al caso más cercano de las fallas valencianas.

Ahora bien, las normas que regulan la protección de la vida, bien proscribiendo el homicidio y la violencia, bien organizando la producción y la distribución de los recursos, no necesariamente tienen que ser igualitarias ni justas. Para empezar porque no es inhabitual que se privilegie a los miembros del propio grupo frente a los de otros. De hecho, los nombres con que muchos pueblos se designan a sí mismos significan también "seres humanos". "Fuera del grupo cerrado, no hay seres humanos" (Benedict 1989: 19). Pero incluso dentro del grupo, aun cuando como regla general se proteja la vida de los miembros, a veces a ciertos sujetos no se les considera miembros, ni siquiera personas, y no se les protege en la misma medida que a los demás. 
Otro ámbito regulado en alguna medida jurídicamente es el del emparejamiento, la reproducción y la crianza. Por supuesto, habrá quien piense que muchas cuestiones familiares son organizadas por otras normas, pero las jurídicas se encargan de las más graves. Así, aunque los grados de libertad sexual varíen de unas sociedades a otras, no se conoce ninguna en la que la sexualidad no esté normada, siendo el orden jurídico el encargado de reprimir las ofensas que se consideran más severas. Enorme importancia tiene también la normativa referida a la reproducción y la crianza, de la que depende la continuidad del grupo. Baste con referirse a la controvertida prohibición del incesto y a la consecuente obligación de la exogamia, presentes en los órdenes jurídicos. Así todo, las transformaciones que sobre todo en las sociedades occidentales se están produciendo demuestran que pautas que hasta hace poco se tenían por universales están dejando de serlo, lo que trae consigo que haya que extremar las cautelas a la hora de afirmar en este ámbito hipotéticos universales culturales.

Otros universales jurídicos no se refieren a normas y principios sino a determinados rasgos del Derecho, por lo que su estudio también corresponde a quienes se ocupan del concepto del Derecho. Por supuesto, los distintos autores, tanto teóricos como antropólogos del Derecho, no se ponen de acuerdo en lo tocante a cuáles son esos rasgos, pero hay dos, combinados en distinta medida, que suelen ser aceptados y cuyo estudio ofrece interesantes noticias relativas a la legitimación y al funcionamiento de los órdenes jurídicos: la autoridad y la fuerza, que se hallan siempre presentes, pero nunca en idéntica proporción (Pospisil 1974: 44 ss.).

También pueden estudiarse como universales del Derecho las dimensiones de éste. Por una parte, la dimensión ideal o ideológica: las normas, principios y valores que forman parte de lo jurídico, que constituyen lo que puede llamarse el Derecho en los libros. Por otra parte, la dimensión práctica: los jueces, la policía, las cárceles, que harían referencia al Derecho en acción. Por fin, el Derecho tendría otra dimensión que suele resultar invisible a los mismos juristas pero que tiene gran importancia, la ritual o ceremonial.

En efecto, una de las cuestiones de la que se ocupa la antropología jurídica y de la que, con alguna excepción, se suelen despreocupar los demás saberes del Derecho, es la de los ceremoniales o ritos jurídicos, ese conjunto de formas que, en relación tanto con la creación como con la aplicación del Derecho, resalta su importancia. En principio, la labor parece obvia: aplicar las teorías de los ritos (Díaz Cruz 1998) al estudio de los ritos jurídicos, de entre los que sobresalen los rituales judiciales (Garapon 2000), en los que no sólo se sigue un procedimiento que ordena la ceremonia, en ocasiones celebrada en suntuosos Palacios de Justicia, sino que además los principales partícipes, quienes la conducen, ocupan los lugares 
relevantes en la sala, visten ropajes distintivos y hasta lujosos, hablan una lengua ininteligible para el común y son respetados, cuando no reverenciados, por el público. A veces alcanzan tanta autoridad que se igualan al mismo rey, caso de los aztecas (León Carbajal 2015: 93). ¿A alguien puede extrañar que a los jueces se les haya llamado sacerdotes de la ley? Parece que Durkheim y sus seguidores tenían razón cuando afirmaban que el Derecho tenía o estaba revestido de un carácter religioso (Durkheim 1993: 80; Mauss 1967: 136; Radcliffe-Brown 1971: 219). Valga la descripción que hizo Tolstoi, nada menos, de un tribunal ruso del siglo XIX:

\footnotetext{
¡El Tribunal!

Todos se pusieron en pie y en el estrado aparecieron los jueces. Primero, el presidente con sus músculos y sus hermosas patillas. Luego el juez de los lentes de oro y de cara sombría [...] Venía, por último, Matviei Nikítchin, el que siempre se hacía esperar [...] El aspecto del presidente y de los vocales, que habían subido al estrado con sus uniformes de cuello recamado en oro, imponía. Ellos mismos lo comprendían así, y los tres, como turbados por su propia grandeza, bajando modestamente la vista, se apresuraron a sentarse en sus sillones tallados (1992: 24-25).
}

Pero si hasta aquí nos hemos referido a los rasgos comunes a los distintos Derechos, ahora hay que apuntar lo obvio, que todos los Derechos son distintos. El método comparativo de la etnología sirve también para dar cuenta de las diferencias jurídicas. Dos cuestiones resultan de especial importancia. Por una parte, la de las razones de las diferencias. Si fuera la naturaleza humana la que explicara el contenido del Derecho, todos los órdenes jurídicos serían iguales o las diferencias resultarían inexplicables, arbitrarias; luego tienen que existir otros motivos que expliquen las diferencias jurídicas. Por otra parte, dado que la perspectiva para analizar las diferencias tanto puede ser sincrónica como diacrónica, nos encontramos con rasgos e instituciones que han sido universales a lo largo de un período histórico pero que han dejado de serlo, lo mismo que habría rasgos e instituciones particulares que se han convertido en universales. Explicar por qué ha ocurrido semejante cambio (por qué la pena de muerte o el patriarcado han dejado de ser universales, por ejemplo) también sería un cometido propio de la antropología jurídica, que así se enfrenta a apasionantes enigmas.

\section{Conclusión}


Llegamos al final, ahora que se acaba de hacer referencia a la pena de muerte y el patriarcado, reivindicando un papel fundamental para la antropología jurídica hoy, el estudio de los derechos humanos (Krotz 2002: 39). No se trata, por supuesto, de que la antropología de los derechos humanos se dedique a la fundamentación de éstos, cuestión propiamente filosófica, sino al estudio comparativo, tanto de su reconocimiento teórico (doctrinal y legislativo) como del respeto práctico, razón por la que, cuando los derechos humanos se pretenden universales, la antropología jurídica resulta indispensable.

Trabalho enviado em 01 de setembro de 2019

Aceito em 06 de fevereiro de 2020 